\title{
Conceptual Framework of a Synthesized Adaptive e-Learning and e-Mentoring System Using VARK Learning Styles with Data Mining Methodology
}

\author{
Oranuch Pantho and Monchai Tiantong
}

\begin{abstract}
Currently, e-learning systems are becoming more popular. This is because e-learning systems provide learners freedom to study with unlimited time and at any location. But, most of the e-learning systems present the same learning content without regard to different learning styles of learners. Many learners have to adapt to different learning styles such as learning content from images which is not specifically targeted at their needs. Meanwhile, other learners may have aptitude in reading or from listening, etc. Therefore, learning and teaching processes are important issues that teachers need to adjust their teaching according to individual learners. If each learner obtains content that aligns with their own learning style, it will lead to more achievement.

The purpose of this research is to synthesize the learning model of adaptive e-learning and e-mentoring system in order to recommend learners and analyze the VARK learning style (VARK is an acronym for visual, aural, read/write, and kinesthetic) by using data mining methodology. The synthesized model consists of four modules which are 1) esaB eluR KRAV eludoM2) VARK Learner Module 3) Content Module and 4) Learning Module.
\end{abstract}

Index Terms-E-learning, adaptive learning, learning style, VARK learning style.

\section{INTRODUCTION}

Learning and teaching by using the e-learning system is a way to enhance learning and teaching capacity. The E-learning system is an evolution of information technology, network technology and multimedia technology to achieve maximum efficiency in education. E-learning systems are now widely accepted because it has the flexibility to adjust content, which will be up to date, provides an opportunity for everyone to learn and gives freedom of research without restrictions of time and location [1]. In addition, e-learning systems are also used as a communication tool between teacher and learner by using modern communication tools such as e-mail, web-board, chat, etc [2]. However, although e-learning is very useful, some e-learning systems are a self-learning system with no influence of achievement for the learner. Some learners may take more time than others to study contents as each learner has different ability to gain knowledge. The recognition of learner depends on individual factors, including experience, interest, aptitude, knowledge, wisdom, and learning plan. These factors influence the learning speed. In traditional e-learning systems, the focus was on the development of presentation rather than the consideration of individuality [3]. And traditional e-learning systems tend to lead to boredom, slow down of learning and underachieving. Therefore, the solution for an effective e-learning system is the development of an adaptive e-learning system [2] by focusing on the learner's learning style. Learning style means the physical characteristic, thought and feeling that individual uses to perceive, responsiveness and interaction with a stable environment. The learning style is one element that will help to enhance the learning process, promote learning motivation and learning performance to learners [4]. As in the research of Suriyakrai, [5] found that the teacher knows the learners learning style, the teacher is able to organize appropriate activities or learning environments. Learners who study in an appropriate environment will higher achievement than a group of learners who have a poorly matched learning environment. Moreover, this learning style is also a tool in order to design learning management or present the appropriate content to learners as an individual [3], [6].

Many researchers have proposed adaptive e-learning, and focusing on the difference between individuals. For example, the researches [7]-[9] proposed a system with path selection, the best learning technique will be adjusted to the appropriate path for each teaching. The research [10] created a decision support system to guide the appropriate path. The research will [11] analyze the learner by using questions. The questionnaire ranges from simple to difficult questions. The answers that the learner does not understand what the content is, then it will create the adaptive navigation to the learner. But all three researches mentioned above have no e-mentoring system which will advise learners automatically. For the research [12], the system will send a quiz to the learners according to their aptitude in 3 levels which are easy, medium and hard. If the system evaluates the learner's answer and discovers that the learner provided a lower score than the specified score, the system will guide learners to repeat the lesson again. All research mentioned above used the method of searching for knowledge of each learners in order to determine the different path of study. Regardless of the ability to recognize different learners, mentioned systems still present the same content to learners who have the aptitudes to different recognition.

\section{RELATED WORK}

The authors are with the Faculty of Information Technology, King Mongkut's University of Technology North Bangkok, Bangkok, Thailand (e-mail: ammubon@hotmail.com, monchai@kmutnb.ac.th).
E-learning systems provide content or information technology or training which e-learning systems use to 
broadcast content through various devices such as computers, internet, intranet, or TV signals, etc. Learners can study independently, anywhere and anytime. Studying with an e-learning system has no fixed learning's path. Learners can choose content that is presented according to experience, need, interests and their own styles [7]. Currently, e-learning system has some restrictions which are 1) the presentation of content and learning activities are the same regardless of the difference between individuals. 2) E-learning systems have no mentoring system to assist automatically during studying called an e-mentoring system. Various methods are available for evaluation of learner's learning style. For this research, the classification method of the learning style using the sensory method is applied. That is the VARK questionnaire as a concept of Fleming [13]. VARK questionnaire is a questionnaire that is very popular as a quite simple learning style [14] and applied practically. The VARK questionnaire can divide the learner's sensory into 4 categories which consists of Visual (V; learning from graphs, charts and flow diagrams), Aural (A; learning from listening, speaking or disputing, Read-Write (R; learning from reading and writing) and Kinesthetic (K; learning from touching, experiment, test activity or experience. In the research [15] which studied the difference between individuals by using VARK questionnaire, found that male and female have different learning style significantly. Teacher should be aware of the learning style of different learners in order to develop appropriate teaching in the future.

In addition, the research presented the adaptive e-learning according to the aptitude of most learners. In the research [1] the learner provided an answer for the online VARK questionnaire and studied e-learning. Then, obtained studying behaviors or used the main web of Web logs to analyze via data mining techniques to find the learning path's content for learners with different learning styles. The mentioned e-learning system can help learners to study more effectively. The research [16] can classify types of learner to course via computer programming according to learning style. This was achieved by an application of data mining which used decision tree methods and grouping as k-means. It was found that learners with different learning styles and teaching aligned with learning styles can help them to achieve more understanding. In the research [17] they used the adaptive e-learning by submitting contents to learners according to their learning styles. Each learner had different learning paths by extracting their learning styles from log files by a technique of Web usage mining and Artificial Neural Network. So, the system is able to adjust the learning path for them as well. However, the research had some restrictions. Learners would be given the same lesson and no tracking system to guide them in case of a miss understanding of content, etc.

From the above restrictions, in order to help the learner obtain content and learning activities which align with interests and aptitude of the learner between individuals must be developed. Thus, the researcher of this paper presents the adaptive e-learning with e-mentoring system using VARK learning style by data mining methodology to synthesize the conceptual framework to create different lessons in 4 modules according to the learning style of VARK. The learners will receive lessons that meet their own learning style. The learner's learning style came from the answer of the VARK questionnaires. Then, data will be analyzed using data mining techniques. The e-mentoring system will recommend steps to the learner through online tools. The e-mentoring system will hopefully be a satisfactory replace for the teacher in the class when not available.

\section{CONCEPTUAL MODEL}

The conceptual framework of synthesize on an adaptive e-learning with e-mentoring system using VARK learning style by data mining methodology is shown in Fig. 1, which consists of 4 modules as follows;

\section{A. VARK Rule Base Module}

VARK Rule Base Module is the learning style storage of all learners. The process of this module has 3 steps; 1) creating a questionnaire which consists of two parts: the first part is the general information of the learner or the independent variable. The independent variable came from the survey of 80 experts' comments in education with 10 years experience of teaching in Chiang Mai Rajabhat University. The second part is the independent variable with VARK questionnaires which is a closed questionnaire. VARK questionnaire has 16 questions with 4 multiple choices. 2) The sample group used the questionnaire to survey 2,000 undergraduate students of Chiang Mai Rajabhat University. 3) The analysis of data mining in order to create rule base, which compares the performance of the classification in VARK learning style, such as Tree (Decision tree C4.5, BNTree), Bayes (Naïve Bayes, Bayes Net) and Rules (Decision table, DTNB).Then, selection of the algorithm with the highest accuracy.

\section{B. VARK Learner Module}

VARK Learner Module is the module that obtains learning styles of the learner. The working process of the module starts with the learner registering to the system. The system will bring the learner's profile in order to match the rule base which comes from the VARK rule base module.

\section{Content Module}

Content module is the module that stores the content of the lessons. The learning content is divided into 4 categories according to the sense of perceptions, such as Visual, Aural, Read/Write and Kinesthetic. Each learning step and content will be aligned with the correct learning style of each learner.

\section{Learning Module}

Learning module is the module about learning and teaching using the VARK learning style. The learning module processes through the LMS. Its responsibility is to the serve e-learning and LMS-learning management system. It will serve the learner respectively, at intervals with the conditions which the teacher has prepared systematically. The learning module has 4 components; 1) Mentor database, the database that stores guidelines for the learner, divided into 4 categories; Visual, Aural, Read/Write and Kinesthetic. 2) Activity, the presented lesson and activities of learning and teaching aligned with the learning style of learners. Learning style of learners comes from the VARK learner module. From activities of learning and teaching for learners, the 
survey of 5 experts comments in education. 3) Agent, this part will record and track learners. If the learner has already studied in the system, repeat again, the e-learning system will present the content to continue learning as previously. 4) Adaptive mentoring, the part that adjusts to be more effective. During the class, there will be a test using adaptive mentoring in order to check tests scores between learners. If the score during class meets the criteria, the system will present the next content to the learner. But, if the score does not meet the criteria, the system will retrieve some recommendations from the Mentor database and the learner has to revert back to the same content again.

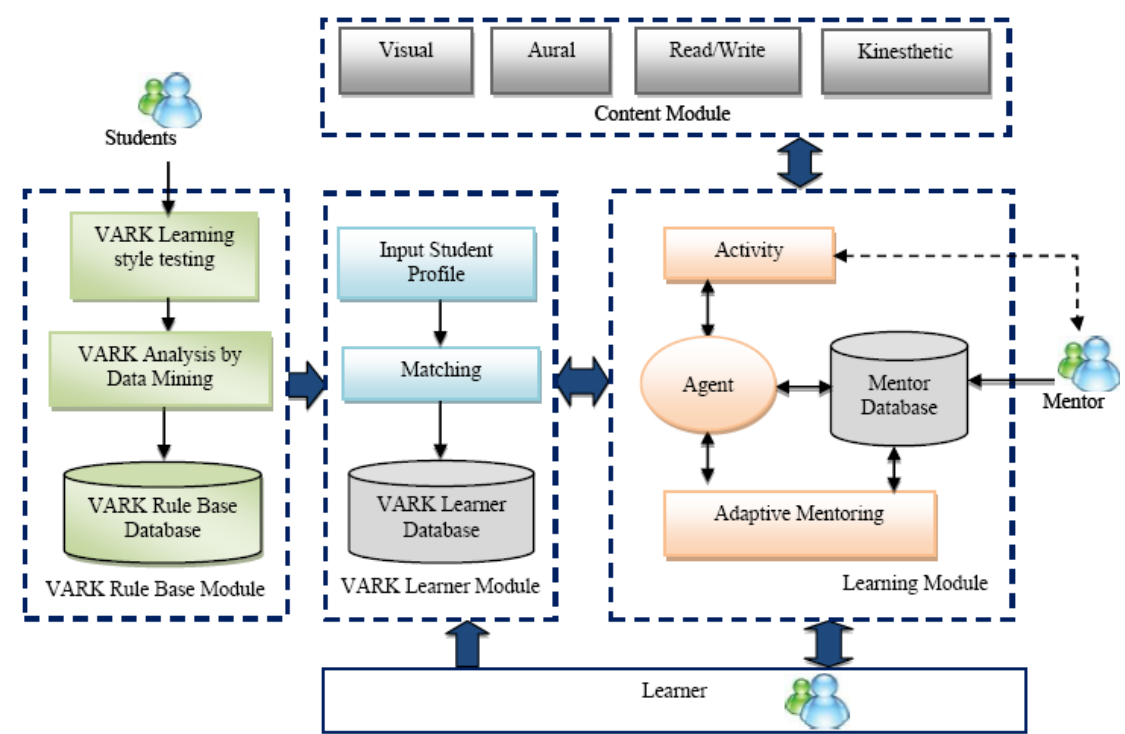

Fig. 1. Framework for adaptive e-learning with e-mentoring system using VARK learning style by data mining.

\section{Evaluation}

The evaluation of the synthesized model was conducted by interviewing 5 experts. The total score of the questionnaires equaled 30 points divided over 5 levels. The result of the evaluation from experts found that all modules are appropriate at a very good level with the total average at 4.47 and the standard deviation equal to 0.73 . When analyzing the various components within the module, it was found that VARK Learner Module and Content Module is the most appropriate with the average at 4.80 . The suitability of the overall synthesized model and the appropriateness of VARK Rule Base Module were also found to be appropriate with an average of 4.40, etc. Details are shown in Table I;

TABLE I: The Evaluation OF THE SyNTHESIZEd Model of ADAPTIVE E-LEARNING WITH THE E-MENTORING SYSTEM BY USING VARK LEARNING STYLE TO ANALYZE WITH DATA MINING METHODOLOGY

\begin{tabular}{lccc}
\hline \hline \multicolumn{1}{c}{ Description } & $\bar{x}$ & S.D. & Evaluation \\
\hline $\begin{array}{l}\text { 1. Appropriateness of VARK } \\
\text { Rule Base Module }\end{array}$ & 4.40 & 1.34 & Very appropriate \\
$\begin{array}{l}\text { 2. Appropriateness of KRAV } \\
\text { eludoM renraeL }\end{array}$ & 4.80 & 0.44 & Most appropriate \\
$\begin{array}{l}\text { 3. Appropriateness of Content } \\
\quad \text { Module }\end{array}$ & 4.80 & 0.44 & Most appropriate \\
$\begin{array}{l}\text { 4. Appropriateness of gninraeL } \\
\text { eludoM }\end{array}$ & 4.20 & 0.44 & Very appropriate \\
$\begin{array}{l}\text { 5. Appropriateness of learning } \\
\text { and teaching process by VARK } \\
\text { learning style }\end{array}$ & 4.20 & 0.83 & Very appropriate \\
$\begin{array}{l}\text { 6. Appropriateness of overall } \\
\text { synthesized model }\end{array}$ & 4.40 & 0.89 & Very appropriate \\
\hline Total Average & 4.47 & 0.73 & Very appropriate \\
\hline \hline
\end{tabular}

\section{CONCLUSION AND FutURE DiRECTIONS}

The purpose of this research was to synthesize adaptive e-learning and e-mentoring system using the VARK learning style with data mining methodology. Learners will obtain lessons that meet their own aptitudes and also support learning which emphasizes on true learner centered learning. This conceptual framework consisted of 4 modules; 1) VARK Rule Base Module 2) VARK Learner Module 3) Content Module and 4) eludoM gninraeL .This conceptual framework was presented to experts by interviewing without structure, it was found that experts opinions towards this synthesized model were very satisfactory with the total average 4.47 (S.D.=0.73). Therefore, this conceptual framework is appropriate to apply to learners who have different learning styles, focusing on 4 categories; Visual, Aural, Read/Write and Kinesthetic.

This research is only a conceptual framework. For the next step, the researcher will bring the synthesized model to the development stage with trials with sample groups in order to find the achievement levels of learners.

\section{ACKNOWLEDGMENT}

The author would like to thank Ministry Science and Technology, Thailand. That support scholarship.

\section{REFERENCES}

[1] H. Ba-Omar, I. Petrounias, and F. Anwar, "A framework for using web usage mining to personalize e-learning," in Proc. $7^{\text {th }}$ IEEE International Conference on Advanced Learning Technologies, 2007, pp. 937-938.

[2] M. Sasakura and S. Yamasaki, "A framework for adaptive e-learning systems in higher education with information visualization," in Proc $11^{\text {th }}$ International Conference on Information Visualization, 2007, pp. 819-824.

[3] A. A. Firte, C. V. Bratu, and C. Cenan, "Intelligent component for adaptive E-learning systems," in Proc. IEEE $5^{\text {th }}$ International Conference on Intelligent Computer Communication and Processing, 2009, pp. 35-38.

[4] M. Koorsse, C. B. Cilliers, and A. P. Calitz, "Motivation and learning preferences of information technology learners in South African secondary schools," in Proc. the 2010 Annual Research Conference of 
the South African Institute of Computer Scientists and Information Technologists, 2010, pp. 144-152.

[5] S. Suriyakrai, "A development of an adaptive web-based learning model for individual differences based on the mastery learning principle to enhance learning achievement and problem solving skills of pharmacy students," Ph.D. dissertation, Dept. Educational Communications and Technology, Chulalongkorn Univ., Bangkok, THA, 2007.

[6] V. Shute and B. Towle, “Adaptive e-learning," Educational Psychologist, vol. 38, pp. 105-114, 2003.

[7] M. Yarandi, H. Jahankhani, and A.-R. H. Tawil, "An adaptive e-learning Decision support system," in Proc. $15^{\text {th }}$ International Conference on Interactive Collaborative Learning, 2012, pp. 1-5.

[8] M. Guan, J. Jia, Y. Yang, and Q. C. Yuhua, "Research on Adaptive e-learning System Using Technology of Learning Navigation," in Proc. $8^{\text {th }}$ International Conference on Computer Science \& Education (ICCSE), 2013, pp. 24-29.

[9] C. Jing and L. Quan, "A complex adaptive E-learning model based on sematic web services," in Proc. International Symposium on Knowledge Acquisition and Modeling, 2008, pp. 555-559.

[10] B. Bontchev and D. Vassileva, "Courseware authoring for adaptive e-learning," in Proc. International Conference on Education Technology and Computer, 2009, pp. 176-180.

[11] G. Weber, "Adaptive learning systems in the World Wide Web," Courses and Lectures International Centre for Mechanical Sciences, 1999, pp. 371-378.

[12] S. U. Khalid, A. Basharat, A. A. Shahid, and S. Hassan, "An adaptive e-learning framework to supporting new ways of teching and learning," in Proc. International Conference on Information and Communication Technologies, 2009, pp. 300-306.

[13] N. D. Fleming, "I'm different; not dumb. Modes of presentation (VARK) in the tertiary classroom," in Proc. the 1995 Annual Conference of the Higher Education and Research Development Society of Australasia, HERDSA, 1995, pp. 308-313.

[14] V. Marcy, "Adult learning styles: How the VARK learning styles inventory can be used to improve student learning," Perspectives on Physician Assistant Education, vol. 12, pp. 117-120, 2001.
[15] E. A. Wehrwein, H. L. Lujan, and S. E. DiCarlo, "Gender differences in learning style preferences among undergraduate physiology students," Advances in Physiology Education, vol. 31, pp. 153-157, 2007.

[16] N. Norwawi, S. Abdusalam, C. Hibadullah, and B. Shuaibu, "Classification of students' performance in computer programming course according to learning style," in Proc. $2^{\text {nd }}$ Conference on Data Mining and Optimization, 2009, pp. 37-41.

[17] S. V. Kolekar, S. Sanjeevi, and D. Bormane, "Learning style recognition using Artificial Neural Network for adaptive user interface in e-learning," in Proc. IEEE International Conference on Computational Intelligence and Computing Research, 2010, pp. 1-5.

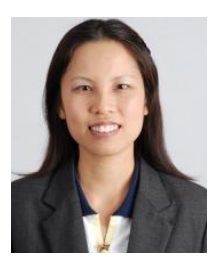

Oranuch Pantho was born in Lamphun Province, Thailand on October 1, 1972. She graduated with a bachelor degree in computer science from Lampang Rajabhat University, Thailand in 1995, she also graduated with a master degree in information technology from King Mongkut's University of Technology North Bangkok (KMUTNB), Thailand in 2001. She now works as a lecturer in the Faculty of Science and Technology at Chiang Mai Rajabhat University, Thailand.

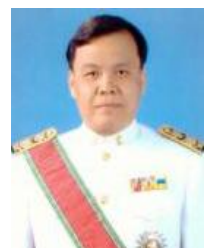

Monchai Tiantong got his B.S. degree in electrical engineering, M.S. degree in electrical, and Tech. Ed. degree curriculum research \& development from King Mongkut's University of Technology North Bangkok (KMUTNB), Bangkok, Thailand. He has been working as an associate professor for more than 20 years in the following faculties, information technology, computer education, and technical education, KMUTNB. He is also a member of AACE, IEEE, ACM, and etc. 